\title{
Make equity essential to expedite change in academia
}

\author{
In response to COVID-19, universities and other education providers pivoted rapidly from in-class learning to digital \\ course instruction. Student tuition was deemed essential, thus swift change ensued. Similarly, if equity, diversity \\ and inclusion are truly deemed essential at those same institutions, change could occur now - not later.
}

Beronda L. Montgomery

n the wake of the COVID-19 pandemic, we have learned that being deemed 'essential' has a range of meanings, both in academia and society at large. From the very start of the pandemic, essential workers included first responders such as the healthcare practitioners who diagnosed and treated patients with COVID-19. Other services were also deemed essential to society, including personnel working at grocery stores, farm workers, delivery workers and transit personnel, as well as custodial workers in hospitals, shops and other essential businesses ${ }^{1-3}$. As a consequence, those working in essential industries were expected to continue to work, despite the increased risk of exposure to SARS-CoV-2. Furthermore, although deemed essential, many of these workers are often underpaid, raising the question of how essential we truly believe such workers to be.

At the same time that society at large was dealing with the pandemic, schools, colleges and universities were also pivoting to altered means of engagement and education to comply with COVID-19 restrictions. Universities immediately began strategizing about how to keep classes in session, and, thus, keep tuition money flowing in. This continuation of incoming funds grew even more crucial as the money from on-campus housing and other services such as catering, hospitality and food services dried up for these institutions. Staff well versed in 'virtual' or online learning, and central to transitioning classes and other forms of engagement to digital platforms, were crucial to enable instruction online. Many of the changes and innovations and the speed at which they occurred - would not have been thought possible before COVID-19. Protracted debate and planning are usually required for even small changes in curricula in most universities. However, during the pandemic, universities recognized that failure to maintain access to classes would halt tuition-based income if face-to-face learning was the only provision, which I believe was a critical factor leading to online learning activities being deemed essential. In prioritizing teaching because of its essentiality, the usual barriers to rapid change in universities were removed.

Transforming systems is hard and slow, at least that is the prevailing rhetoric - if not deeply rooted belief - driving practices in higher education. Yet in this pandemic we have seen that when your system depends on a function (such as tuition), things can change quickly to ensure that essential resources remain available. As access to courses was deemed 'essential' for the survival of institutions, rapid change and digital innovations ensued ${ }^{4}$.

As one who analyses and closely studies systems - including where gaps and barriers exist, as well as where promise, possibility and real change have the potential to emerge - I have been fascinated with watching what materializes as possible when a service or goal is deemed essential in the midst of this current global crisis. As we have traversed the coronavirus pandemic, racial unrest and widespread recognition of persistent impacts of racism resurged in the United States in response to events including those with Black birder Christian Cooper $^{5}$ and the murder of George Floyd at the hands of police ${ }^{6}$. Universities responded, as did a great number of business entities, with statements professing solidarity with and commitment to Black Americans, including public written statements and verbal declarations on the part of university administrators that 'Black Lives Matter.' Institutions made commitments to review and improve practices intended to promote racial justice, and to promote representation among and support for Black students, staff and faculty. Yet despite these aspirational statements, real actions and strategies to mitigate or eliminate anti-Black racism have been much slower to emerge, despite the well-documented racial disparities in academia $^{7}$. Many of the anti-racism statements issued by universities seem to fall into the category that has been aptly described by Sara Ahmed as providing a means for words, or policies, to intentionally substitute for action and transformation of institutions ${ }^{8}$. Changes promised by institutions in the wake of responding to anti-Black racism have limped along or failed to materialize altogether, perhaps because they have not been deemed essential, unlike online course delivery during a pandemic.

Now that I have seen what can happen when an issue or challenge is seen as essential and critical to the very survival of academic institutions due to the tragic reality of COVID-19, I wonder what would happen if ensuring justice and equity in terms of access and success were truly seen in a similar light. I wonder what rapidity and change we would see in diversity, equity and inclusion if the leaders of our institutions saw equity and justice for all students, staff and faculty as essential to their very existence and ongoing survival.

We have seen powerful examples of what happens when a single individual or a small group in the science community declares an activity essential. For example, based on recognizing the importance of undergraduate research experiences for individuals in groups historically underrepresented in science, technology, engineering and mathematics (STEM), which have been shown to increase success and persistence for these students ${ }^{9}$, Johnson et al. quickly created an online summer research programme for such students in microbiology $y^{10}$. By deeming these opportunities essential, this group planned, activated and successfully carried out the National Summer Undergraduate Research Program (NSURP) $)^{10}$. Additionally, many Black scientists spent a great deal of 2020 recounting lived experiences in STEM spaces and higher education to celebrate and call for much-needed attention to the realities of being Black in STEM, such as Black Birders Week, Black Botanists Week, 
Black in Microbiology Week, and many others ${ }^{5,11}$. These individuals spearheaded these efforts through grassroots organization because they deemed these conversations and associated activities essential.

\section{"I wonder what would happen if ensuring justice and equity in terms of access and success} were truly seen in a similar

\section{light."}

No matter how many statements are made to communicate that equity, diversity, inclusion and justice are essential in academic spaces, the transformation of institutions into places that prioritize, actively pursue and hold themselves accountable for pursuing and maintaining these values will only come when we deem it essential in word and deed. There are persistent and long-standing disparities in STEM spaces and STEM education, even if scientists and academicians too frequently assume that education and research spaces work based on meritocracy, and that they are somehow insulated from larger societal challenges such as systemic racism, gender biases and other disparities. The reality is that many of the societal injustices we witness happen both outside of - and indeed fully inside of - the academy. When we walk through the gates of our universities or the doors of our classrooms, our laboratories or leadership spaces, systemic inequities persist and exist in the spaces that are supposed to be the great equalizer of education. Listening to the many challenges and traumas that marginalized individuals have shared about their experiences in these spaces can be difficult. It is often hard for individuals to make a personal assessment detailing how they may have individually contributed to maintaining whiteness and systemic bias in spaces they have viewed as largely meritocratic. It can be much easier to point the finger outward than to ask ourselves the difficult questions, such as whether one has expressed a commitment to equity yet consistently walks a path of inequitable engagement and assessment that occurs daily at our institutions; whether and how one contributes to these problems; and how one can help to address these issues. But marginalized individuals within a community notice when colleagues and leaders commit to promoting equity, justice, diversity and inclusion, and when they actively fail to work to ensure that such commitments come to fruition.
Part of the problem with instituting such changes is related to what aspects of our work are also deemed essential. In academia and science, we spend most of our time focused on the outputs of our work, such as the number of students and postdoctoral scientists we have recruited and trained, post-study or post-training placements for these individuals, the numbers and journal placements of papers published, the number of research funding dollars we bring in, and the prestigious awards we win. These are the metrics usually deemed as essential for academic success, and much less frequently do we examine, assess or actually hold ourselves accountable for the effective means of how these outputs are achieved (for example, through culturally competent or equitable mentoring or leading). The distinction is crucial. You can have stellar metrics but you may have accomplished them while causing damage to people in the process. We must hold ourselves accountable for how work outputs are achieved, as failure to do so is one of the ways in which biases persist in academic spaces. We need intentionality in holding ourselves responsible for how we do our work, in addition to rewarding people for what work is accomplished. Such intentionality should include considering the specifics of how outputs are generated in our evaluation of the progress of individuals and the success of institutions. Efforts in this regard would include adapting established review and promotion practices or creating new ways to foster these principles, thereby ensuring structures of accountability and more rapid change.

The COVID-19 pandemic has taught me that if we want to move beyond incremental advances in progress towards diversity, equity and inclusion, change can happen quickly if we deem these issues to be essential. By doing so, these transformations in academic spaces should also help to identify those best positioned to lead the way to change we so desperately need. To accomplish this, we may need to draw on abilities we demonstrate in regards to being excited about the unknown, such as a microbiologist's fascination with unculturable bacteria ${ }^{12}$ or our understanding that organisms in the natural world (such as plants) that have access to the right environment and resources tend to thrive and grow better than their counterparts ${ }^{13,14}$.

My greatest hope is that we understand the critical roles we have in improving our ability to care about equity, justice, diversity and inclusion, and in demonstrating strategic tending and leadership of higher education providers to promote equitable growth and success ${ }^{15}$. If we want to see progressive movement towards establishing and maintaining equitable spaces, the first step is to deem these changes as essential to the very survival of our communities and institutions.

\section{Beronda L. Montgomery (D) 1,2,3凶}

${ }^{1}$ Department of Energy-Plant Research Laboratory, Michigan State University, East Lansing, MI, USA. ${ }^{2}$ Department of Biochemistry and Molecular Biology, Michigan State University, East Lansing, MI, USA. ${ }^{3}$ Department of Microbiology and Molecular Genetics, Michigan State University, East Lansing, MI, USA.

$凶_{e-m a i l: m o n t g 133 @ m s u . e d u}$

Published online: 21 December 2020 https://doi.org/10.1038/s41564-020-00845-0

References

1. Mitchell, Z. \& Dearing, T. What it means when you're deemed an essential worker. WBUR https://www.wbur.org/ radioboston/2020/04/16/essential-workers-grocery-custodial (2020).

2. Ortega, B. He's considered an 'essential' worker. What he feels, though, is underpaid and at risk. $C N N$ https://www.cnn. com/2020/06/26/us/farmworker-coronavirus-invs/index.html (2020).

3. Stewart, E. Essential workers are taking care of America. Are we taking care of them? Vox https://www.vox.com/ covid-19-coronavirus-explainers/2020/4/23/21228971/ essential-workers-stories-coronavirushazard-pay-stimulus-covid-19 (2020).

4. Strielkowski, W. Preprint at Preprints https://doi.org/10.20944/ preprints202004.0290.vl (2020).

5. Mallenbaum, C. \#BlackBirdersWeek, \#BlackInNeuro: Black scientists, physicians are using hashtags to uplift. USA Today https://www.usatoday.com/story/life/2020/08/04/ blackinneuro-blackinchem-can-hashtagshelp-black-scientists-build-community-spotlightexcellence/5541431002/ (2020).

6. Blain, K. N. Violence in Minneapolis is rooted in the history of racist policing in America. The Washington Post https://www.washingtonpost.com/outlook/2020/05/30/ violence-minneapolis-is-rooted-history-racist-policing-america/ (30 May 2020).

7. Barber, P. H., Hayes, T. B., Johnson, T. L. \& Márquez-Magaña, L. Science 369, 1440-1441 (2020).

8. Ahmed, S. On Being Included: Racism and Diversity in Institutional Life (Duke University Press, 2012).

9. Shadding, C. R., Whittington, D., Wallace, L. E., Wandu, W. S. \& Wilson, R. K. SAGE Open https://doi.org/10.1177\% 2F2158244016657143 (2016).

10. Johnson, M. D. L., Baltrus, D. A. \& Gardy, J. Nat. Microbiol. 5, 1311-1313 (2020).

11. Wu, K. J. Black microbiologists push for visibility amid a pandemic. The New York Times https://www.nytimes. com/2020/09/28/science/black-microbiology-week.html (28 September 2020)

12. Montgomery, B. L. mSphere 5, e01046-20 (2020).

13. Montgomery, B. L. Plant Cell 32, 3372-3375 (2020).

14. Montgomery, B. L. Pub. Phil. J. https://doi.org/10.25335/M5/ PPJ.1.1-3 (2018).

15. Montgomery, B. L. J. Values-Based Leadersh. 13, 16 (2020).

\section{Acknowledgements}

Some of the thoughts discussed herein were developed and shared in my blog post entitled 'The Power and Peril of Being Deemed 'Essential" at: http://www.berondamontgomery.com/reflect/ the-power-and-peril-of-being-deemed-essential/.

Competing interests

The author declares no competing interests. 